\title{
Edgar Morin e o pensamento complexo: UMA POSSIBILIDADE COGNITIVA
}

\author{
Ruy Rocha Junior
}

\begin{abstract}
RESUMO
Este artigo tem como pretensão apresentar alguns elementos teóricos da teoria da complexidade presente em Edgar Morin. A proposta segue por um viés de aproximar o leitor da compreensão de complexidade e completude; a polidisciplinaridade e a transdiciplinaridade com vista em destacar como a abordagem de Morin almeja despertar o conhecimento que, segundo o autor, esta adormedico.

Palavras-chave: Edgar Morin, saberes, educação do futuro, pensamento complexo.
\end{abstract}

Edgar Morin usa o termo "complexidade" alegando que não se pode fugir do desafio do reconhecimento da existência da multiplicidade. Na educação deve-se questionar as diferentes complexidades, lidando com o desafio do ser humano complexo. Por um lado, é possivel acreditar que a complexidade conduz à simplicidade; por outro, não se deve confundir complexidade e completude.

A complexidade diz respeito ao caráter multidimensional do real, "ao mundo empírico, à incerteza, à incapacidade de ter certeza de tudo, de formular uma lei, de conceber uma ordem absoluta”. Máxima oriunda de sua crítica:

* Licenciado em Filosofia e História, Pós-graduado em Sociologia, Globalização e Cultura na Fundação Escola de Sociologia e Política de São Paulo; Mestre em Ciências da Religião; Autor das obras: Cultos de Mistério: Dionisio e as origens ocultas do cristianismo e Morte e Ressurrreição no Egito Antigo: A influência da religião egpcia no cristianismo; ambas pela Fonte Editorial. 
A ciência do homem não possui um princípio que enraíze o fenômeno humano no universo natural, nem um método apto a aprender a extrema complexidade que o distinga de qualquer outro fenômeno natural conhecido. Seu arcabouço explicativo ainda é o da física do século XIX, e sua ideologia implícita continua sendo a do cristianismo e do humanismo ocidental: a natureza sobrenatural do homem. (MORIN, 2015, p.17).

Quando Morin aventa tais críticas propõe uma nova - e livre abordagem, onde a complexidade de pensamento livrará as pessoas do determinismo atual. Para tal, Morin diz que a polidisciplinaridade e a transdiciplinaridade ${ }^{1}$ permitem que os aluno (as) aprendam as disciplinas separadamente.

Todavia o pensamento complexo reorganizará este saber, de forma que o mesmo seja usado em conjunto para o rompimento do paradigma atual, já que normalmente:

Qualquer conhecimento opera por seleção de dados significativos e rejeição de dados não significativos: separa (distingue ou disjunta) e une (associa, identifica); hierarquiza (o principal, o secundário) e centraliza (em função de um núcleo de noções chave); essas operações que se utilizam da lógica, são de fato comandadas por princípios "supralógicos" de organização do pensamento ou paradigmas, princípios ocultos que governam nossa visão das coisas e de mundo sem que tenhamos consciência disso. (MORIN, 2015, p.10).

Morin acredita existir uma ignorância no desejo de almejar a exatidão no conhecimento profundo, pois essa ignorância afasta do conhecimento real.

Dessa forma, a doença do saber remete a uma inteligência cega, onde predomina a visão segmentada do conhecimento, de maneira oposta a uma visão global. Frente a esse questionamento, o professor de ontem e hoje - deve contribuir para que seus alunos não se prendam a essa inteligência, despertando-os para a percepção do conhecimento real, integral.

1 Nota do autor: A polidisciplinaridade se caracteriza pela "associação de disciplinas em torno de um projeto ou de um objeto que lhes é comum". Transdisciplinaridade é um conceito da educação que compreende o conhecimento de uma forma plural. É uma corrente de pensamento mais aberta e que busca dar uma resposta ao método tradicional de divisão de disciplinas. 
Morin destaca a questão do desenho e intenção complexos, o esboço e o projeto complexos, acrescentando que em nossa concepção de mundo, temos lacunas que impedem enxergar o real, tal qual o mito da caverna de Platão.

Essas lacunas são definidas como "rachaduras e as fendas em nossa concepção de mundo que não só viraram enormes aberturas, mas também estas aberturas deixam entrever (...) os fragmentos ainda não ligados entre si".

Dessa forma, o sujeito interior deve ter ligação com o exterior, procurando um ponto de equilíbrio com o meio e o sistema. Assim, o cérebro do homem se tornará mais eficiente que a cibernética. Pois ao se relacionar com o mundo externo o sujeito vai interiorizando saberes, e desenvolvendo a razão.

Sendo assim, é necessária a pesquisa para não se correr o risco de permanecer na ignorância. 0 ápice de sua obra retrata que a complexidade faz parte da ciência e da vida cotidiana, onde o sujeito assume papéis que o fazem se inserir ainda mais num universo complexo. Na medida em que se estabelece relações num determinado grupo, ele assume identidades, e vive a multidisciplinaridade permeada por complexidades.

Dessa maneira, na medida em que se caracteriza os processos complexos, Morin aceita uma contradição: "a relação ordem/desordem/ organização surge, pois, quando se constata empiricamente que fenômenos desordenados são necessários em certas condições, em certos casos, para a produção de fenômenos organizados, os quais contribuem para o crescimento da ordem. (MORIN, 2015, p.63).

0 ser humano é um sujeito autônomo, que pode se colocar "centro do seu próprio mundo" (MORIN, 2015, p.65). Por isso ele pode pensar e agir por si, na verdade o sujeito deve partir das situações de desordem para chegar a uma ordem/organização das coisas e fatos. Para tratar do complexo é necessário auto-organização, o que libertando daquela inteligência cega das disciplinas multifacetadas. No entanto, um sistema deve criar suas próprias determinações, sem romper ligações com os demais sistemas no qual a sociedade se interliga.

Ao abordar a questão da complexidade e ação, Morin se refere a ação como um desafio, de forma que ela acabe se tornando uma estratégia que parte da atitude inicial para diferentes ações direcionais. 
Ele acredita na ação como o reino concreto e, às vezes, vital da complexidade (MORIN, 2015, p.81). A complexidade não afasta a clareza, nem a ordem ou o determinismo; mas os considera insuficientes para o esclarecimento das verdades universais. Essa complexidade abordada pelo autor diz respeito a várias situações do cotidiano. À partir do momento em que o homem interage numa determinada sociedade, seus conhecimentos produzidos e acumulados, ele já experimenta as situações complexas. Muitas vezes o conhecimento restrito ajuda somente superficialmente, porém, é necessário aprofundar direcionando ao conhecimento amplo. Na Epistemologia da complexidade, Edgar Morin cita todas as ideias de complexidades, admitindo que essas ideias são incapazes de unificar uma conclusão, salientando que a ciência também possui limites.

Para tanto, cabe à Filosofia da Educação o questionamento, a discussão, a tomada de decisões e ações visando contribuir para a formação integral do ser humano.

\section{CONSIDERAÇões Finais}

Assim, as instruções de Edgar Morin auxiliam os educadores à construirem um ensino cada vez mais humano, ético e sustentável.

Com base na quebra dos paradigmas tradicionais, que tanto vigoram em salas de aula quadrilateras e sufocantes, Morin destaca a urgência da "reagrupação dos saberes que buscam a compreensão do universo".

Sua teoria do pensamento complexo busca restituir o "conhecimento que se encontra adormecido", reagrupando unidade e diversidade.

Com o passar dos tempos a evolução da universidade fragmentou o saber em estudos por área. Seu pensamento da complexidade visa inserir "a competência especializada num contexto natural, na globalidade".

E quando Morin fala de pensamento simples, remete as ciências em visão clássica. A principal noção de sua proposta busca o dialogo entre os pensamento simples e o complexo. Nele o conhecimento não fragmentado ajudaria a entender o mundo de forma contextualizada, 
abrangente e completa; transformação onde os alunos se entendem como parte de um sistema.

Para exemplificar a ineficiência do pensamento especializado, temos as ciências econômicas, destinadas a solucionar questões importantes fundamentadas exclusivamente na matemática e na lógica. Dessa maneira os economistas não têm conseguido predizer as crises; muitos têm problemas em saberes além dos seus; como, por exemplo, as angustias da morte, que alguns sabem discorrer sobre ela como própria da existência humana. Mas a dicotomia do câncer assombra, pois é uma "explosão de vida que gera a morte". Como?

Novamente cabe ilustrar a nossa ideia com os gregos; o que Morin propõe é um conhecimento complexo compartilhado, semelhante ao Encyclios Paidêia (educação circulo de cultura?). As palavras correspondem a um conjunto variado de conhecimentos indispensáveis à formação cultural do cidadão grego.

A palavra Encyclios deu origem a enciclopédia, que é uma coletânea de textos que agrupa diversos conhecimentos.

E a inteligência da complexidade seria um modelo semelhante ao renascentista, que integra diversos saberes ao todo. Não confundir com misturar, trata-se mesmo de integra-los, de forma que ecoem em uníssono. 0 que é o ser humano? Cada disciplina irá definir à sua maneira, mas matematica, biologia, física, cosmologia, matematica, química e mesmo a filosofia são incapazes de responder uma pergunta de tamanha envergadura.

Hoje temos as palavras da vez; Finlândia, metodologias ativas, "gamificação", flipped classroom e tantas que servem como perfumaria para o real propósito da educação. Não que essas metodologias estejam na contramão, ou mesmo não sirvam para educar. Talvez os "modismos" as coloquem como centro, e mesmo que o discurso afirme que o aluno é o protagonista, paira a dúvida: Será? Temos observado que os países que adotaram metodologias ativas o fizeram como políticas públicas, especificidade responsável pelo sucesso das mesmas. Mas e aqui no Brasil? Até onde tal discurso é apenas mercado? E até que ponto podemos aplicar as boas práticas sem nos distanciar de nossa própria realidade? Cabe também a Filosofia, tão esquecida e posterga- 
da, levantar questões sobre o diálogo entre as metodologias ativas e o pensamento complexo dos sete saberes da educação. Não seria sensato reagrupar todas as ferramentas existentes de forma a aproximar-se um pouco mais os componentes curriculares?

Vale arrostar a ideia!

\section{REFERÊNCIAS}

ARANHA, Maria Lúcia De Arruda. Filosofia Da Educação. 3. ed. São Paulo: Moderna, 2006.

ARANHA, Maria Lúcia de A. História da educação e da pedagogia - geral e do Brasil. 3. ed. São Paulo: Moderna, 2013.

GADOTTI, Moacir. História das Idéias Pedagógicas. 8. ed. São Paulo: Ática, 2011.

GALLO, S. A Filosofia e seu Ensino: conceito e transversalidade. Ethica (Rio de Janeiro), v. 13, p. 17-35, 2006.

GAUTHIER, Clermont; TARDIF, Maurice. A Pedagogia: teorias e praticas da Antiguidade aos nossos dias. Petropolis: Editora Vozes, 2010.

JAPIASSÚ, Hilton. MARCONDES, Danilo. Dicionário Básico de Filosofia. 3. ed.revista e ampliada. Rio de Janeiro: Zahar, 1999. p. 130.

LUCKESI, Cipriano Carlos. Filosofia da Educação. São Paulo: Cortez, 1994. 175p.

MORIN, Edgar. Introdução ao pensamento complexo. trad. 5. ed. São Paulo: Editora Cortez, 2015.

Os sete saberes necessários à educação do futuro. trad. 2. ed. revisada. São Paulo: Editora Cortez, 2017.

SAVIANI, Dermeval. Educação: do senso comum à consciência filosófica. 11. ed. São Paulo: Cortez, 1996.

WALLERSTEIN, Immanuel. Para abrir as ciências sociais. trad. São Paulo, Editora Cortez, 1996. p.14. 